\title{
Invention of the Guide Catheter Irrigation Monitoring Device for Neuroendovascular Therapy
}

\author{
Ayca Ozkul, M.D., Jong-Hyun Park, M.D., ${ }^{2}$ Dong-Seung Shin, M.D., Ph.D., ${ }^{2}$ Ali Yilmaz, M.D., ${ }^{3}$ Bum-Tae Kim, M.D., Ph.D. ${ }^{2}$ \\ Department of Neurology, Adnan Menderes University, Aidyn, Turkey \\ Department of Neurosurgery, ${ }^{2}$ Bucheon Hospital, Soonchunhyang University College of Medicine, Bucheon, Korea \\ Depatment of Neurosurgery, ${ }^{3}$ Adnan Menderes University, Aidyn, Turkey
}

Objective : The thromboembolic events during neuroendovascular therapy (NET) are the major complications of concern that can be occasionally fatal. The thrombotic occlusion of the guide catheter for NET is thought to be the risk of the thromboembolic events. We have developed an idea for inventing the monitoring system of the continuous irrigation through the guide catheter. We herein present a unique invention of the guide catheter irrigation monitoring device.

Methods : We have developed ideas for preventing the thrombotic occlusion of the guide catheter. In order to design a convenient device working in the practical use, we have consulted and shared the ideas with the electrical engineers about putting the invention.

Results : The guide catheter irrigation monitoring device (GCIMD) consisted of three parts of optical sensor, main body and electric adapter. In brief, the basic principles of working of the GCIMD are as follows. The optical sensor is attached to the dripping chamber of the line to irrigation solution. The main body had the small light and speaker to make an alarm sounds. The sensor monitors the dripping of flush solution. If the dripping stops more than three seconds, a warning alarm has been activated. So, the operating physicians can concentrate and check the guide catheter irrigation. After the use of the GCIMD, there was no major thromboembolic complication in conjunction with the thrombotic occlusion of the guide catheter in our institute.

Conclusion : We have developed a brilliant invention of the GCIMD for NET.

Key Words : Thromboemblism · Endovascular techniques · Angiography · Catheter obstruction · Ischemia · Infarction.

\section{INTRODUCTION}

Cerebral angiography $(\mathrm{CA})$ is still the gold standard in the evaluation of cerebrovascular pathologies. Furthermore endovascular management of such diseases is continuing to become more prevalent ${ }^{1}$. The treatment choices for cerebrovascular diseases are widening with novel devices which have been improved in recent years. On the other hand CA and neuro-endovascular therapy (NET) have a risk of procedure related symptomatic cerebral ischemia which was reported as $1-3 \%$ in previous studies ${ }^{3,8}$. Additionally clinically silent ischemic events detected by diffusion weighted magnetic resonance imaging (MRI) were seen $23 \%$ of patients undergoing $\mathrm{CA}^{2}$. Similar embolic events can be also seen in extracranial

- Received : January 5, 2017 •Accepted : February 6, 2017

- Address for reprints : Bum-Tae Kim, M.D., Ph.D.

Department of Neurosurgery, Soonchunhyang University Bucheon Hospital, 170 Jomaru-ro, Wonmi-gu, Bucheon 14584, Korea Tel : +82-32-621-5059, Fax : +82-32-621-5016, E-mail : bumtkim@schmc.ac.kr

This is an Open Access article distributed under the terms of the Creative Commons Attribution Non-Commercial License (http://creativecommons.org/licenses/by-nc/4.0) which permits unrestricted non-commercial use, distribution, and reproduction in any medium, provided the original work is properly cited. 
angiography ${ }^{6}$. In a transcranial doppler study a high number of microembolic signals was detected during angiography ${ }^{4)}$. Although the occurrence of procedure-related stroke from CA is low, clinicians should consider that any stroke may be devastating to the patient. In order to prevent such a complication, angiography catheters are typically connected to a continuous flush of a heparinized solution during neurointerventional procedures. Techniques or hardware that further reduce this risk should be constantly evaluated. There is a need of monitoring system of the continuous irrigation through the guide catheter. We herein present a unique invention of the guide catheter irrigation monitoring device (GCIMD) for NET.

\section{MATERIALS AND METHODS}

In order to prevent cerebral ischemia due to thromboemboli during NET, we designed a convenient device to be used in practical life. Accumulation of blood inside the catheter lumen between injections is one potential source of thrombus formation. Therefore angiography catheters should be connected to a continuous flush of heparinized solution (Fig. 1). The device should warn whenever continuous flush is stopped and should be easier to use in practice. We have worked with electrical engineers to develop our imaginary device. We have also got a patent from Korean Government with a patent number of 10-1604719 at 14-3-2016.

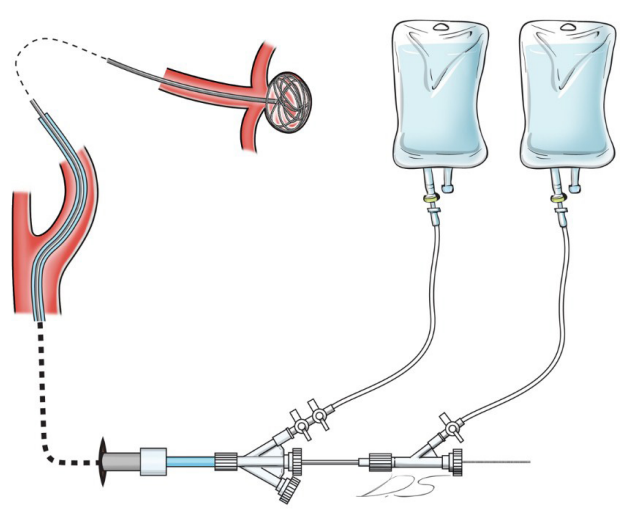

Fig. 1. In order to prevent thromboembolism, angiography catheters should be connected to a continuous flush of heparinized solution during NET ${ }^{7)}$. Reprint from the Essentials of Neurossurgical Procedures and Operations, with permission from the Korean Neurosurgical Society. Copyright 2015 by the Korean Neurosurgical Society. NET : neuroendovascular therapy.

\section{RESULTS}

Our device is called as GCIMD. It consisted of three main parts; the optical sensor, the main body and the electric adapter (Fig. 2).

\section{Optical sensor and main body}

The optical sensor is attached to the dripping chamber of the line to irrigation solution (Fig. 1). The main body constituted with the small light diode and speaker which makes an alarm sounds. The sensor monitors the dripping of the continuous flush. If the dripping stops more than three seconds, an alarm has been activated in order to warn to the operating physicians. After the use of the GCIMD, there was no major thromboembolic complication in conjunction with the thrombotic occlusion of the guide catheter in our institute.

\section{Electric adapter}

Electric adapter has been charged by electric source of 110 voltages and/or 220 voltages.

\section{DISCUSSION}

CA is becoming more important since its role in making diagnosis and novel cerebrovascular disease treatment strategies have been improved. In order to have better results in neurointerventional procedures, development of better new techniques and equipments have become essential over the past 20 years. Thromboembolism is a well known complication which may occur after various angiographic procedures, including CA and coronary angiography ${ }^{1,5)}$. Cerebral thromboembolic events are one of the important complications after the proce-
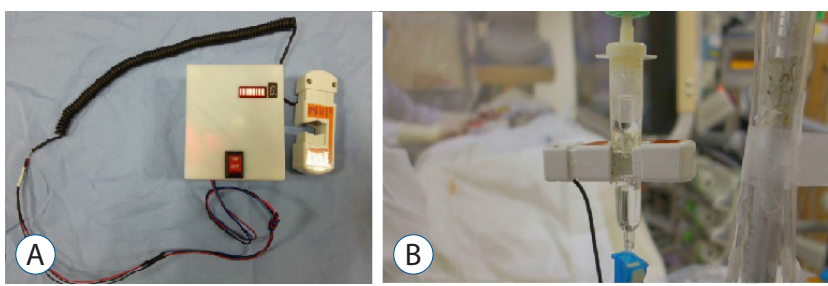

Fig. 2. GCIMD was consisted of three main parts; the optical sensor, the main body and the electric adapter (A) which can be easily used in practice (B). GCIMD : guide catheter irrigation monitoring device. 

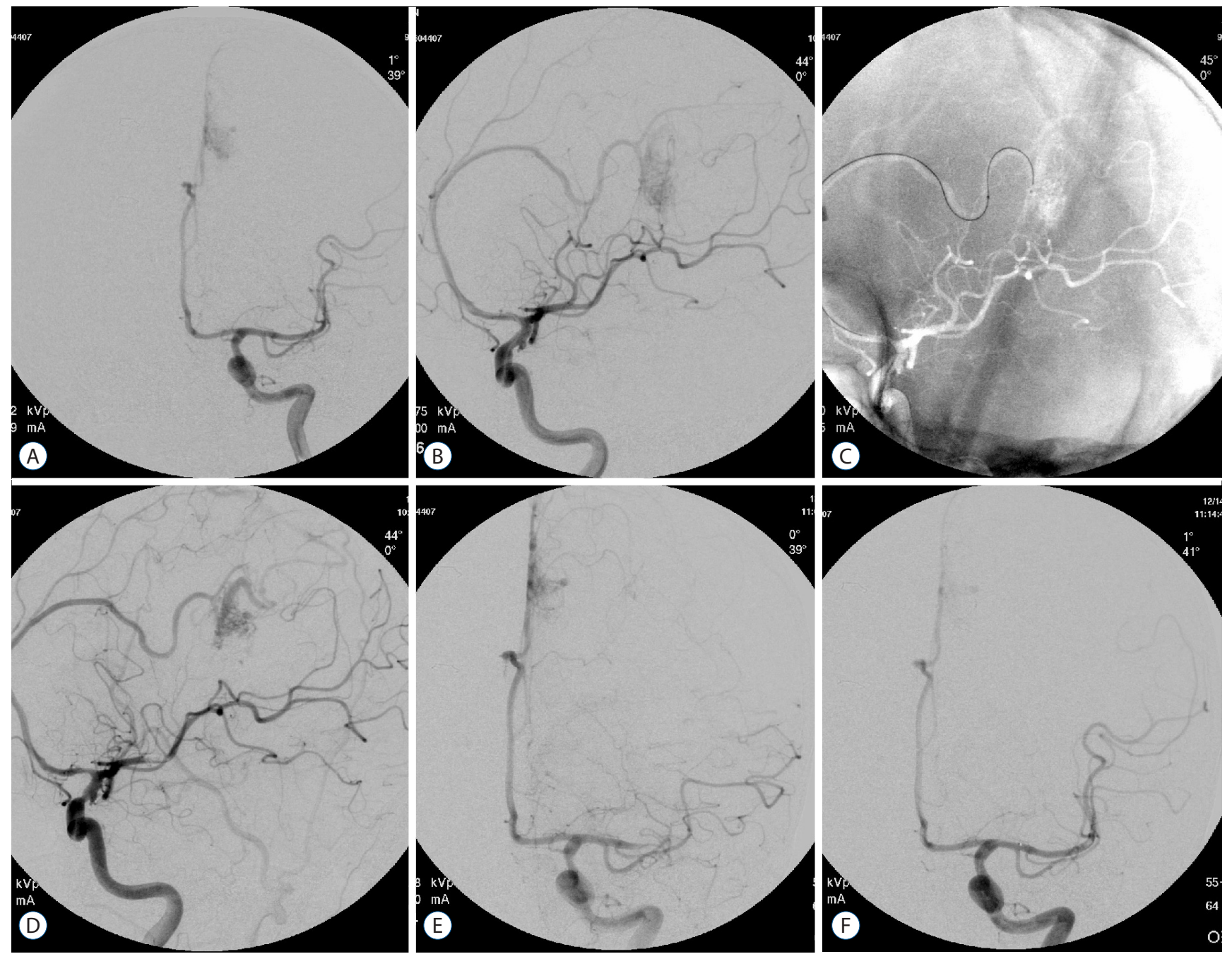

Fig. 3. A 55 years old male who had left pericallosal AVM (A, B). The embolic MCA occlusion was detected during the glue embolization procedure on pericallosal AVM (C, D). The occluded MCA was completely recanalized by the intra-arterial urokinasse thrombolysis (E, F). AVM : arterio-venous malformation, MCA : middle cerebral artery.

dure. Although the substantial risk for procedure-related symptomatic cerebral ischemia has been reported as $1 \%$ to $3 \%$ in previous studies ${ }^{3,8)}$ the main problem is the silent ischemic events which are more common. In a study 100 patients after CA had diffusion weighted MR imaging (DW-MRI) and 42 silent ischemic lesions consistent with acute emboli infarcts in 23 patients were detected after the procedure ${ }^{2}$. In order to prevent inadvertent emboli the neurointerventionists should keep the catheter hub filled with heparinized saline by dripping or injection.

Although CA and NET are relatively safe, the clinicians should be aware of the fact that better results depend on careful approach and better techniques to avoid embolic events.
The use of continuous heparinized flush in closed angiographic systems is one of the easier methods in practice. However sometimes decrease of the pressure of the system or any kind of problem including catheter deformity, tortuosity or system failures which enable continuous flush of heparinized saline cannot be detected during the procedure and unfortunately this may cause embolic ischemia easily ${ }^{9)}$.

We had experienced an embolic occlusion on the ipsilateral proximal middle cerebral artery (MCA) during the glue embolization for the 55 years old male who had a pericallosal arteriovenous malformation (Fig. 3A-D). The embolus on MCA came from the guiding catheter which enable the continuous flush of heparinized saline cannot be detected during the pro- 
cedure. Fortunately, the occluded MCA was completely recanalized by the intra-arterial urokinasse thrombolysis (Fig. 3E, F). With this experience, we have developed an idea to know whether the continuous saline infusion was stops during NET. Therefore we decided to develop a unique device giving an alarm whenever the continuous saline infusion stops in a closed angiographic system. We have consulted and discussed our opinion with the electrical engineers for our invention. GCIMD included three parts; optical sensor, man body and electric adapter. It is easy to use in daily practice. If the dripping stops more than three seconds, a warning alarm has been activated. We believe that after the use of GCIMD neurointerventionist can concentrate more on the CA and NET procedures.

From January 2009 through December 2015, to date we have applied 189 cases who treated by endovascular treatment for unruptured intracranial aneurysms by means of monitoring system of the continuous irrigation through the guide catheter. No cases showed embolic occlusion during intraprocedural angiography while monitoring by GCIMD. A followup DW-MRI carried out the day following the procedure revealed $67.8 \%$ of cases showed tiny thromboembolic spots without neurological symptoms. In our institute after the use of GCIMD, no major thromboembolic complication in conjunction with the thrombotic occlusion of the guide catheter was detected. Further observations and studies can be also done to see its effects on silent embolic events.

\section{CONCLUSION}

In conclusion, neurointerventionists should be careful against thromboembolic complications. We have developed GCIMD for the continuous heparinized saline infusion. In our institute there was no major thromboembolic complica- tion after the use of this unique device.

\section{- Acknowledgements}

This work was supported by the Soonchunhyang University Research Fund.

\section{References}

1. Ahn SH, Prince EA, Dubel GJ : Basic neuroangiography : review of technique and perioperative patient care. Semin Intervent Radiol 30 : 225-233, 2013

2. Bendszus $M$, Koltzenburg $M$, Burger $R$, Warmuth-Metz $M$, Hofmann E, Solymosi $L$ : Silent embolism in diagnostic cerebral angiography and neurointerventional procedures: a prospective study. Lancet 354 : 1594-1597, 1999

3. Heiserman JE, Dean BL, Hodak JA, Flom RA, Bird CR, Drayer BP, et al. : Neurologic complications of cerebral angiography. AJNR Am J Neuroradiol 15 : 1401-1407; discussion 1408-1411, 1994

4. Jurga J, Nyman J, Tornvall P, Mannila MN, Svenarud P, van der Linden J, et al. : Cerebral microembolism during coronary angiography: a randomized comparison between femoral and radial arterial access. Stroke 42 : 1475-1477, 2011

5. Kaufmann TJ, Huston J 3rd, Mandrekar JN, Schleck CD, Thielen KR, Kallmes DF : Complications of diagnostic cerebral angiography: evaluation of 19,826 consecutive patients. Radiology 243 : 812-819, 2007

6. Omran $H$, Schmidt $H$, Hackenbroch $M$, Illien $S$, Bernhardt $P$, von der Recke $\mathrm{G}$, et al. : Silent and apparent cerebral embolism after retrograde catheterisation of the aortic valve in valvular stenosis: a prospective, randomised study. Lancet 361 : 1241-1246, 2003

7. Shin DS, Kim BT : Basic endovascualr techniques: Coil embolization of aneurysms in Kim BT (eds) : Essentials of Neurosurgical Procedures and Operations, ed 1. Seoul : Panmun, 2015, pp133-142

8. Willinsky RA, Taylor SM, TerBrugge K, Farb RI, Tomlinson G, Montanera $W$ : Neurologic complications of cerebral angiography: prospective analysis of 2,899 procedures and review of the literature. Radiology $227: 522-528,2003$

9. Yilmaz A, Ozkul A, Shin DS, Im SB, Yoon SM, Kim BT : Morphological assessment of cadaveric radial, brachial and subclavian arteries: a neurointerventional approach. J Korean Neurosurg Soc 58 : 499-503, 2015 